\title{
EDUCAÇÃO EM ENGENHARIA - ATIVIDADES EXTRACURRICULARES
}

DOI: 10.37702/2175-957X.COBENGE.2021.3366

Clarissa Maria Rodrigues de Oliveira - clamarirodrigues@hotmail.com Universidade Federal do Piauí

Rua Rommel Santos Portela 23

64010-818 - Teresina - PI

Maria do Socorro Ferreira dos Santos - socorroferreira@ufpi.edu.br Universidade Federal do Piauí

RUA: LUCRÉCIO DANTAS AVELINO 560

64007-500 - TERESINA - PI

Resumo: $O$ presente estudo apresenta como objetivo a investigação da relação dos alunos de Engenharia de Produção da Universidade Federal do Piauí (UFPI) com atividades extracurriculares, averiguando como estas contribuem para a formação qualificada do alunado por meio da percepção dos estudantes entrevistados. Assim, aplicou-se questionários aos estudantes de Engenharia de Produção da UFPI, devidamente matriculados no período de 2017 a 2020. Os resultados revelam um relativo desconhecimento dos discentes em relação ao que representa o tripé universitário, principalmente no que se refere à extensão, além disso percebeu-se a inserção destes tardiamente em programas extracurriculares, uma vez que a participação majoritária ocorre somente a partir do sexto (6 $\left.6^{\circ}\right)$ período de curso, ainda, notou-se que o desenvolvimento de atividades extraclasse de extensão por parte de acadêmicos de graduação permite aos mesmos desenvolver habilidades pessoais, profissionais, além de técnicas e métodos científicos. Portanto, é relevante a intervenção da universidade como informadora e motivadora da participação do acadêmico em atividades extracurriculares.

Palavras-chave: Educação em Engenharia. Atividades extracurriculares. Formação qualificada. Tripé universitário. Extensão. 


\section{EDUCAÇÃO EM ENGENHARIA - ATIVIDADES EXTRACURRICULARES}

\section{INTRODUÇÃO}

A Lei no 9.394, de 20 de Dezembro de 1996, estabelece as diretrizes e bases da educação nacional, nesse sentido, contido no capítulo IV, o artigo 43 trata da finalidade da educação superior, no qual consta que se deve incentivar a criação cultural, 0 desenvolvimento científico, bem como o pensamento crítico e reflexivo, além disso, dispõe que é importante a apresentação do estímulo à pesquisa e investigação científica, de maneira a desenvolver a ciência e a tecnologia, outrossim, informar, por intermédio do ensino, os problemas do mundo presente, desenvolvendo o conhecimento do homem e do meio em que o mesmo vive, além dos conhecimentos culturais, técnicos e científicos que integram o patrimônio da humanidade. E, por fim, promover a extensão contribuindo com a prestação de serviços especializados para a sociedade, e instigando a participação da população e divulgando conquistas e benefícios gerados aos externos diante dos projetos realizados dentro da instituição, no tocante a ciência, cultura e tecnologia.

Dessa forma, segundo Borato et al. (2018), a indissociabilidade entre os mesmos proporciona o desenvolvimento e a promoção de conhecimento técnico e científico que contribui para a formação de profissionais qualificados e com anseio de transformação social. Logo, é de extrema importância compreender os impactos dos projetos extracurriculares na formação pessoal e profissional dos discentes de maneira a formar profissionais melhores qualificados e preparados para a convivência e responsabilidade social, assim como para o ramo de trabalho que pretendem seguir.

Diante do exposto, o objetivo geral do presente trabalho é investigar a relação do aluno da Engenharia de produção da UFPI em projetos extracurriculares e constatar a importância na formação discente, para isso, aplicou-se questionários para discentes participantes de atividades extracurriculares do curso de engenharia de produção da Universidade Federal do Piauí (UFPI) devidamente matriculados do período de 2017 a 2020, buscando analisar a percepção dos entrevistados sobre a influência da participação do acadêmico nas atividades curriculares durante a graduação para sua formação profissional.

Esse estudo mostra-se relevante, uma vez que, busca-se compreender a relação destes com o tripé universitário e entender as contribuições das atividades extraclasse para a formação acadêmica e pessoal dos alunos de engenharia de produção da UFPI, além disso, os dados coletados bem como a interpretação dos mesmos proporcionará conhecimento para o desenvolvimento de possíveis intervenções para o problema da evasão no ensino superior, especialmente na UFPI, além de contribuir para o enriquecimento da literatura acadêmica, de maneira a fornecer subsídios para o aprimoramento do ensino de Engenharia de Produção, com vistas à inserção precoce do aluno em atividades extracurriculares.

\section{REFERENCIAL TEÓRICO}

Guersola, Cirino e Steiner (2016) afirmam que é função da universidade promover o preparo técnico profissional dos discentes para a atuação no mercado de trabalho, além de incentivar o desenvolvimento de atividades ligadas a pesquisa, aperfeiçoando a técnica e a metodologia científica, o pensamento crítico, reflexivo, criativo e investigativo, deixando- 
os aquém dos problemas sociais contemporâneos, assim, com o apoio da universidade, participação dos discentes e maior atuação dos mesmos, possibilita-se uma formação de qualidade e completa para os profissionais de engenharia, uma vez que favorecem a participação destes em atividades extraclasse.

Ainda, os mesmos autores afirmam que, na lei № 9.394, de 20 de dezembro de 1996, o ensino superior deve estar relacionado a formar um profissional qualificado para 0 mercado de trabalho, com a promoção de meios eficazes para o aperfeiçoamento da atuação, dentre outras vertentes relacionadas à cultura, pesquisa, ciência, tecnologia e sociedade. Complementa-se que no Brasil demanda-se por engenheiros pesquisadores, "com formação apropriada para atuar dentro das empresas, especialmente em processos de inovação" (BORGES E ALMEIDA, 2013 citado por GUERSOLA, CIRINO E STEINER, 2016). Ainda conforme a LDB/96 há outras formas de aprendizagem além do ensino e da pesquisa, associados ao contato do discente com a sociedade, de maneira a aproximá-los aos problemas cotidianos atuais, transformando e progredindo o espaço que habita (GUERSOLA, CIRINO E STEINER, 2016).

Para Ferreira et al. (2019) o desenvolvimento educacional do aluno não deve estar focado apenas no ensino de novas tecnologias, mas também despertar "a criatividade, a liderança, a inovação e o empreendedorismo", ademais, para os profissionais de Engenharia de Produção, o processo de aprendizagem deve inserir o desenvolvimento de competências e habilidades primordiais na indústria 4.0, além da capacidade de articular e resolver problemas, trabalhar em equipe e a utilização de tecnologias que promovam a inovação e o empreendedorismo.

Assim, conforme Chaves, Barbosa e Therrien (2017) a monitoria acadêmica foi percebida como modalidade utilizada para auxiliar o processo ensino-aprendizagem dada à necessidade para a formação do aluno, posteriormente, esta foi incluída no planejamento das atividades de ensino, pesquisa e extensão das instituições de ensino superior (IES), formação profissional essa fortalecida, tanto para o aluno como para quem exerce o papel de monitor, possibilitando vivências e experiências no contexto universitário.

Além disso, projetos de pesquisa contribuem de diversas maneiras na formação do estudante, na área acadêmica é possível citar o envolvimento do pesquisador na produção de conhecimento, assumindo contato direto com professores e pesquisadores da área, além de melhorar o desempenho acadêmico, já no que tange o profissional, a pesquisa oportuniza a socialização e interação do estudante com outros profissionais mediante a participação em congressos, grupos de pesquisas e publicações em revistas científicas, por fim, pessoalmente, o estudante desenvolve o senso de compromisso, responsabilidade e maturidade (CALAZANS, 2002, apud. PINTO, 2017).

Já no campo da extensão Para Silva (2011) a extensão universitária tem a finalidade de transmitir o conhecimento produzido com a sociedade interna externa, de maneira a socializá-lo e prover um ambiente de aprimoramento e desenvolvimento de habilidades e aprendizados para alunos e professores diante da relação da teoria com a prática. Por meio dessa, possibilita-se a preparação do aluno como transformador social do meio onde está inserido por intermédio de uma intervenção no mundo, no qual estimula a capacidade crítica e a aptidão investigativa, permitindo a conscientização dos reais problemas da comunidade e das pessoas que coabitam esse espaço de maneira a compreender suas diferenças e respeitá-las (CRUZ ET. AL., 2012).

\section{METODOLOGIA}

O presente estudo caracteriza-se como uma pesquisa aplicada, no qual como procedimento aplicou-se o método monográfico ou estudo de caso, em que, de acordo com 
Marconi e Lakatos (2013), corresponde a um estudo realizado com determinada comunidade, população, grupo ou instituição tendo como finalidade a determinação de padrões e generalizações a respeito do conteúdo pesquisado. Quanto ao método científico corresponde-se ao indutivo, uma vez que, conforme os mesmos autores tratam da admissão de teorias baseadas na apuração de verdades particulares. Por fim, a abordagem constitui-se como quantitativa, na medida que tem-se a finalidade de quantificar as respostas dos alunos entrevistados na busca de dados que representam o todo, como também qualitativa, visto que objetiva-se dar significado e discutir acerca do que for encontrado.

Logo, elaborou-se um questionário com a finalidade de examinar a percepção dos discentes do curso de engenharia de produção da UFPI em relação às influências da participação do acadêmico em projetos de ensino, pesquisa e extensão na formação pessoal e profissional, ademais entender a relação do aluno da UFPI com o tripé universitário e como as práticas de ensino, pesquisa e extensão se relacionam com gestão de conhecimento sob a visão dos alunos

Após a aprovação da pesquisa pelo Comitê de Ética e Pesquisa da Universidade Federal do Piauí (CAEE $n^{\circ}$ 07837119.3.0000.5214), procedeu-se com a explicação do tema e objetivo da pesquisa, bem como a apresentação do Termo de Consentimento Livre e Esclarecido - TCLE, aos discentes que optaram pela participação na pesquisa, além disso, assegurou-se sigilo e privacidade nessa pesquisa, preservando a identidade dos estudantes participantes. Obtendo-se um total de 38 respostas de discentes do curso em questão devidamente matriculados no período de 2017 a 2020.

Por fim, os dados coletados foram tratados estatisticamente, realizando a análise e interpretação dos mesmos, empregando gráficos e tabelas informativos, assim como, constatando fatos que proporcionam respostas às investigações, oportunizando uma discussão dos resultados e construção das considerações finais.

\section{RESULTADOS E DISCUSSÃO}

Com a finalidade de compreender a relação dos discentes da UFPI com o tripé universitário, utilizou-se de questionários semiestruturados, obtendo trinta de oito (38) respostas. Dessa forma, indagou-se ao participante da referente pesquisa se o mesmo tem conhecimento acerca dos três (3) pilares universitários, sendo perceptível que a maioria dos alunos envolvidos em algum tipo de projeto, seja este de monitoria, pesquisa e/ou extensão, reconhece ter conhecimento sobre os três pilares que regem o ambiente da universidade e que são responsáveis pela formação do aluno $(84,2 \%)$.

No entanto, apesar da participação e do envolvimento direto com os programas ofertados pela UFPI e com o corpo docente do curso, 15,8\% desses alunos afirmam não conhecer. Dados mais expressivos são apresentados por Santos et al. (2016), o qual realizou um levantamento das atividades extracurriculares de estudantes de diversos cursos da Universidade Federal de Ouro Preto (MG), expondo que 46\% dos estudantes não tem conhecimento a respeito dos pilares universitários, discutindo ser um percentual alto diante da importância desses na contribuição para a formação do discente.

Assim, buscando-se investigar qual dos tipos de programas o alunado apresenta dificuldade de assimilar o conceito, questionou-se sobre a compreensão dos mesmos em relação à extensão, pesquisa e monitoria. No que concerne ao conhecimento do conceito de extensão verifica-se que $78,9 \%$ dos participantes declararam conhecer o conceito de extensão, ainda assim, 21,1\% não compreendem esse tipo de processo de aprendizagem, dificultando sua aplicação na universidade. Todavia, na pesquisa de Santos et al. (2016) esse dado é mais acentuado e preocupante, apontando que $87 \%$ dos alunos entrevistados 
não conhecem o conceito de extensão universitária. No que se refere aos programas que envolvem a pesquisa, notou-se que dos discentes avaliados, 92,1\% revelam compreender o conceito de pesquisa, sendo que 7,9\% não.

Nesse sentido, Amaral (2010) observa, por meio de entrevistas aplicadas a discentes, que a maioria destes afirma possuir contato com o significado de pesquisa apenas no ensino superior, o qual comprova a importância da instituição de ensino superior na formação do profissional, uma vez que a escola a nível básico não proporciona a busca pelo conhecimento investigativo, dessa maneira, os discentes apresentam barreiras quanto ao estímulo a participar de projetos de pesquisa, uma vez que há o desconhecimento por parte destes em relação do que é a pesquisa e como esta contribui para a formação

Já $100 \%$ dos alunos julgam tem conhecimento sobre o conceito de monitoria, esse fato pode estar atrelado a maior aproximação desses com o programa, uma vez que estes têm a oportunidade de uma aproximação mais facilitada com monitores anteriores que os auxiliam em disciplinas cursadas desde a entrada do aluno no ensino superior, além de um ingresso mais simples para a participação no programa, o qual permite a inscrição do aluno desde o terceiro período. Logo, interrogou-se aos alunos entrevistados sobre em que semestre os mesmos começaram a participar de algum programa extracurricular ofertado pela UFPI, apresentado no gráfico da Figura 1.

Figura 1: Semestre que iniciaram a participação em algum projeto de monitoria, pesquisa e/ou extensão

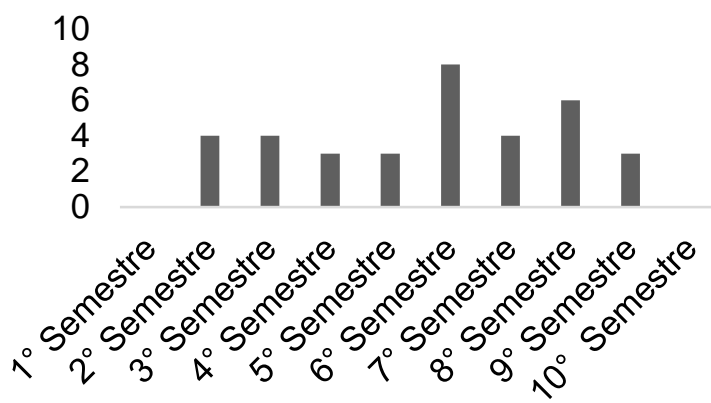

Fonte: Autores (2019)

Como visto na Figura 1, quatorze (14) discentes afirmaram iniciar um projeto ainda quando estavam na primeira metade de duração curso, isto é do primeiro ao quinto período, correspondendo a um total de $35,90 \%$ dos discentes, já a segunda metade corresponde a $53,85 \%$, ou seja, vinte e um (21) alunos afirmaram ter iniciado um projeto do sexto ao décimo período, e 10,25\% não responderam, dessa forma, é notório que a maioria destes $(53,85 \%)$ despertou-se para a participação em um projeto de ensino, pesquisa ou extensão mais tardiamente, depois da metade do curso. De maneira análoga, Rosa et al. (2017) constatou que os estudantes extensionistas entrevistados no seu trabalho desenvolveram seus trabalhos durante um período que oscilou entre o quinto $\left(5^{\circ}\right)$ e 0 nono $\left(9^{\circ}\right)$. Evidenciando que atividades extracurriculares ligadas a ensino, pesquisa e extensão são efetuadas por discentes mais veteranos ao curso, isso posto, é necessária uma intervenção da universidade com a finalidade de promover o incentivo ao acadêmico a participação em atividades extracurriculares em relação aos três pilares da IES.

Do mesmo modo afirmado por meio da pesquisa de Souza, Bianchi e Souza (2016), o qual busca-se averiguar quando seria o ideal para incentivar os alunos na realização de atividades complementares pela perspectiva do discentes do curso de Ciências Contábeis da Universidade Federal do Rio Grande do Sul, compreendendo que para a maioria destes (67\%), o estímulo a atividades extracurriculares devem ocorrer desde o primeiro 
semestre, com o intuito do mesmo organizar e escolher melhor as atividades que condizem com seu perfil, de maneira a agregar ao currículo acadêmico e profissional.

Ainda, conforme os mesmos autores, quanto ao entendimento dos créditos complementares, percebe-se que $43 \%$ dos discentes adquirem informações pertinentes ao assunto por intermédio do contato com colegas, seguido de docentes, com $27 \%$, e pelo portal da faculdade, com $18 \%$, também citaram familiares e outros, igualmente com $6 \%$. Logo, tais dados expõem a pertinência das IES em despertar o interesse nos estudantes em conhecer as oportunidades oferecidas pela universidade e atividades extracurriculares, apresentando enfoque nos três pilares da universidade brasileira nos primeiros períodos da graduação, por exemplo, com a introdução de palestras referentes em disciplinas iniciais ao curso.

Visto que percebe-se um menor conhecimento dos alunos quanto aos programas de extensão, além das dificuldades de verificar a interação do tripé universitário, buscou-se averiguar particularidades dos discentes que praticam essa atividade extracurricular.

Logo, 18 estudantes da UFPI atuantes em projetos de extensão foram entrevistados, verificando que as principais facilidades destacadas pelos mesmos referem-se a relação e comunicação com os extensionistas, as atividades que poderiam ser realizadas individualmente, elaborar as ferramentas de gerenciamento e o relatório, estudar sobre 0 tema, o trabalho em grupo e adaptar-se ao local e disciplinas no intercâmbio, já em relação às principais dificuldades citaram igualmente o trabalho em grupo como empecilho, no entanto a maioria afirmou apresentar obstáculo a ter que falar em público, também citaram dificuldades em ter ideias, conseguir identificar a teoria na prática, obter material atualizado, no desenvolvimento da pesquisa bibliográfica, na busca por patrocínio para um dos projetos de extensão, na coletar dados e na apresentação de seminários.

Logo, perguntou-se se eles superaram as dificuldades, 64,71\% afirmaram que sim, $23,53 \%$ que não e $11,76 \%$ não responderam, para os que responderam sim, questionouse como estes às superaram, obtendo como maior resultado o auxílio e orientação do professor responsável, além disso, citaram maior contato com pessoas externas, realização de rodas de conversas, apresentações de trabalhos que auxiliaram no desenvolvimento da oratória e da perda do medo de falar em público, conversas com membros do projeto e pesquisas sobre o tema.

Em prosseguimento, quando interrogou-se aos alunos se os mesmos verificaram a relação ensino/pesquisa e extensão com a participação como bolsista e/ou voluntário no projeto de extensão, a maioria afirmou que $\operatorname{sim}(58,82 \%)$ e 41,18\% disseram não. Apesar disso, esse dado é preocupante, uma vez que uma parcela considerável desses alunos não foi capaz de identificar essa relação, sendo assim, Pivetta et al. (2010, apud, DE PAULA et al., 2019) reiteram que a interação entre ensino, pesquisa e extensão é relevante para a formação profissional, possibilitando uma visão sistêmica, técnica, multidimensional, crítica e de transformação social, o que proporciona "a fusão de aspectos técnico-científicos, éticos, políticos, econômicos e sócio-culturais".

Dessa forma, é indubitável auferir ao estudante, durante o sequenciamento do projeto, a percepção da integração entre o tripé universitário na dinâmica de aprendizagem. Ademais, para Santos (2012) o ensino é vinculado à transferência do conhecimento científico e técnico para a formação de profissionais, a pesquisa à investigação de novos saberes e produção de conhecimento para o aprimoramento constante do ensino e a extensão tem finalidade de difundir as informações e o aprendizado para além do ambiente acadêmico, cumprindo sua função social.

Para as contribuições acadêmicas que os projetos de extensão proporcionaram para o participante, elaborou-se o gráfico da Figura 2. As alternativas são de múltipla escolha, possibilitando ao estudante marcar mais de uma delas. 
Figura 2: Contribuições do Projeto de Extensão para a formação acadêmica

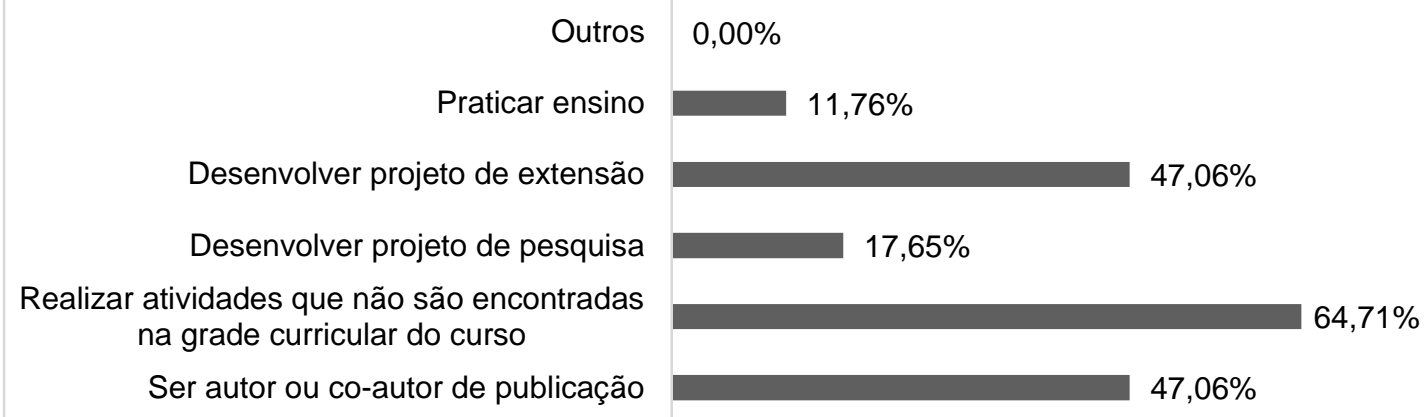

$0,00 \% 10,00 \% 20,00 \% 30,00 \% 40,00 \% 50,00 \% 60,00 \% 70,00 \%$

Fonte: Autores (2019)

Conforme a Figura 2, realizar atividades que não são encontradas na grade curricular do curso foi uma contribuição na formação acadêmica para $64,71 \%$ dos alunos participantes da extensão, seguidamente, 47,06\% citam, igualmente, a colaboração em ser autor ou co-autor de publicação e desenvolver projeto de extensão, seguido por desenvolver projeto de pesquisa, com $17,65 \%$ e praticar ensino com $11,76 \%$, nenhum citou outros. Já as contribuições da extensão para o desenvolvimento pessoal apresentam-se na Figura 3, sendo que as opções são de múltipla escolha.

Figura 3: Contribuições do Projeto de Extensão para o desenvolvimento pessoal

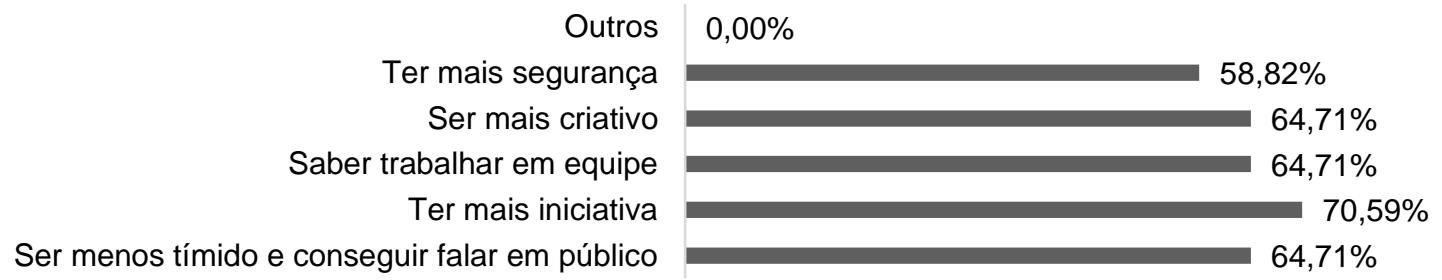

Fonte: Autores (2019)

Nota-se, por intermédio da Figura 3, que a extensão contribuiu para $70,59 \%$ dos estudantes terem mais iniciativa, já, igualmente, $64,71 \%$ do alunado considerou ser mais criativo, saber trabalhar em equipe e ser menos tímidos e conseguir falar em público, assim como 58,82\% acreditam ter mais segurança. Nesse sentido, Santos, Rocha e Passaglio (2016) reconheceram que os projetos de extensão possibilitam ao participante uma maior reflexão entre teoria e prática, em que os alunos têm a oportunidade de praticar os conhecimentos assimilados em sala de aula, capacitando-os também, para articular e solucionar problemas cotidianos profissionais, além disso, revela-se que a extensão permite a imersão do aluno no mercado de trabalho e a observação das diversas possibilidades de atuações, propiciando novas perspectivas profissionais ao acadêmico, bem como o "desenvolvimento da postura ética e crítica sobre a prática profissional, acadêmica e pessoal". Portanto, essas contribuições para a formação do aluno por intermédio da extensão mostram a relação desta com o ensino e a pesquisa.

Similarmente, Rosa et al. (2017), realizam um estudo com a intenção de identificar a percepção de acadêmicos de enfermagem, bolsista de um projeto extensionista, acerca das contribuições deste para a formação dos mesmos no exercício profissional, além da avaliação da aprendizagem a nível acadêmico e pessoal, por meio da aplicação de questionários, constatando que estes afirmaram a possibilidade ampliar conhecimentos já 
assimilados e compreender novos, desenvolver pesquisas, participar de eventos científicos para a divulgação dos resultados, auxílio para o desenvolvimento do Trabalho de Conclusão de Curso (TCC), uma vez que os mesmos adquiriram experiência na elaboração de trabalhos acadêmicos, além de outras habilidades pessoais, como de coleta e análise de dados, elaboração de aulas e a melhora da capacidade de trabalhar em equipe e de falar em público.

Ainda segundo o mesmo autor, em relação ao processo ensino-aprendizagem, os extensionistas relataram a oportunidade de conciliar a teoria com a prática, havendo a aplicação do conhecimento adquirido em sala de aula, permitindo a fixação do conteúdo por meio de um meio diferenciado de aprendizagem, também verificou-se que os orientadores atuavam como estimuladores do ensino, no entanto a prática foi fator essencial para o encorajamento dos discentes para a permanência no projeto, constituindo um processo contínuo de aprendizagem, por intermédio da aplicação e construção de novos conhecimentos. Adiante, indagou-se acerca da percepção dos alunos sobre o papel de um projeto de extensão em uma universidade pública, apresentado na Figura 4. Novamente, a questão é de múltipla escolha.

Figura 4: O papel de um Projeto de Extensão em uma universidade pública

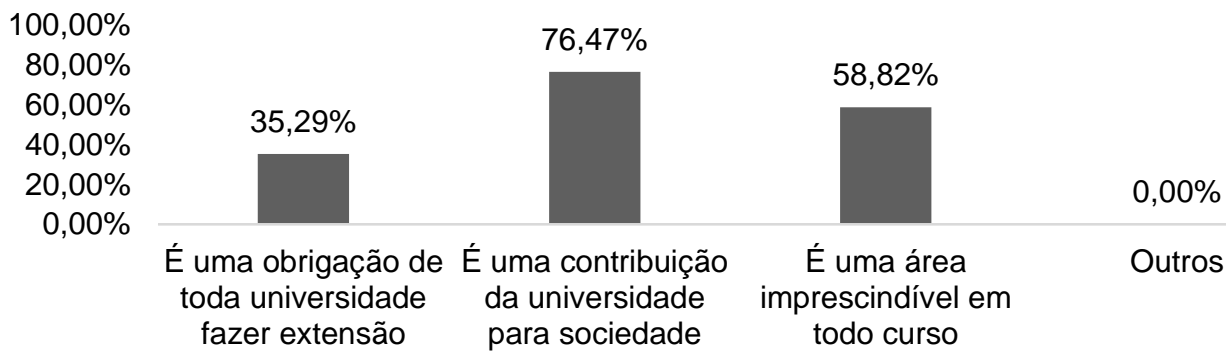

Fonte: Autores (2019)

Segundo a Figura 4, para 76,47\% dos discentes a extensão é uma contribuição da universidade para a sociedades, já para 58,82\% esta é uma área imprescindível em todo curso e 35,29\% consideram que é uma obrigação de toda universidade fazer extensão.

Outrora, indagando sobre o que recomendariam para um bom desempenho nas atividades de extensão, a maioria dos respondentes citou a criatividade, seguida do acompanhamento do docente, do trabalho em equipe, da dedicação e motivação, outros pontos foram mencionados de maneira mais amena, como iniciativa, boa comunicação com professor e extensionistas, disciplina, planejamento e estabelecimento de metas, proatividade, incentivos financeiros, além da afinidade com o projeto desenvolvido. Por fim, dentre as motivações para a participação na extensão, os alunos apontaram com maior frequência o interesse pelo tema abordado, seguidamente, o maior estímulo para participação está relacionado ao currículo, como forma de adquirir experiência e buscar um diferencial, além disso, o impacto do projeto na sociedade foi bastante mencionado, por fim também citaram o convite para cooperar com o projeto, a busca por aprendizado em novas áreas, potencial para seguir carreira acadêmica, superação da timidez, realização de network, trabalhar com outras pessoas e aplicar os conhecimentos técnicos da engenharia.

Semelhantemente, Silva (2011) aborda em sua dissertação, as experiências de estudantes envolvidos em projetos de extensão universitária, assim, como motivação para a participação nos projetos, os estudantes relataram, principalmente, a questão de almejar obter conhecimento de maneira a compreender melhor as teorias e aplicações da área de formação, uma vez que por meio das atividades extensionistas possibilita-se uma aplicação 
prática e mais próxima da realidade profissional, assim, o autor afirma que a extensão contribui como um "exercício preparatório" para o cumprimento da atividade da profissão.

Também descreveu-se o anseio por adquirir mais experiência de forma a auferir conhecimentos específicos para a área de formação e entrar no mercado de trabalho, além disso, para discentes de licenciatura, os projetos de extensão contribuíram para auxiliar a prática da docência, ademais, ainda houve relato de estudantes que obtiveram motivação prática que inclui desejo por horas extras, melhoria do currículo, auxílio financeiro por intermédio das bolsas de iniciação a extensão, elaborar um artigo com os dados das atividades extensionistas, bem como motivação social (SILVA, 2011).

\section{CONSIDERAÇÕES FINAIS}

Essa pesquisa teve como objetivo avaliar a relação do aluno da Engenharia de produção da UFPI com as atividades extracurriculares e constatar a importância na formação discente, dessa forma, com a realização de questionários direcionados a esse público foi possível obter respostas e alcançar as metas anteriormente propostas, logo, pode-se perceber um relativo desconhecimento dos discentes de engenharia de produção da UFPI em relação ao que representa o tripé universitário, sendo então responsabilidade da universidade buscar promover o conhecimento sobre essas diversas formas de qualificar a formação dos alunos, seja acadêmica, pessoal e/ou profissionalmente, intencionando a inserção mais precoce desses alunos nos diversos programas de ensino, pesquisa e extensão, uma vez que notou-se a participação majoritária destes somente a partir do quinto $\left(6^{\circ}\right)$ período de curso.

Nesse sentido, o presente estudo apresenta relevância, uma vez que foi possível compreender a relação do discente com o tripé universitário, ademais as resposta permitiram identificar dificuldades e facilidades apresentadas pelos discentes para as atividades de extensão, uma vez que foi a categoria que os alunos mostraram conhecer menos, logo, possibilitou-se averiguar as contribuições desta para a formação dos mesmos, mostrando a relação desta com o ensino e a pesquisa, assim, as particularidades e problemáticas dos projetos de extracurriculares envolvendo o curso de Engenharia de Produção da Universidade Federal do Piauí apresentadas auxiliam na tomada de decisões afim de melhorar a oferta dessas atividades, como o relativo desconhecimento do conceito de alguns programas, e o aperfeiçoamento da evolução dos mesmos como forma de contribuir notarialmente na formação acadêmica e profissional do alunado.

A percepção dos alunos diante de suas experiências nos programas e projetos da universidade proporciona um melhor entendimento para o planejamento das ações destes de maneira a atrair o discente, como as motivações destes para a participação dos programas, sendo mais atreladas a busca pelo conhecimento, aquisição de experiência, currículo acadêmico e desenvolvimento de habilidades pessoais para alunos extencionistas, acarretando o interesse do estudante na participação pela busca das diversas formas de conhecimento na universidade, além de motivar a reflexão da participação do tripé universitário na formação do estudante universitário.

Outrossim, é importante a intervenção da universidade, por meio da implementação de aulas, por exemplo, nas disciplinas introdutórias do curso, de maneira a possibilitar uma visão mais assertiva aos alunos sobre as oportunidades de desenvolvimento pessoal e profissional que os estudantes podem ter ao ingressarem em programas de monitoria, pesquisa e extensão, tendo como ponto primordial a orientação destes de como participar, agir, quais atribuições e atuações necessárias.

Destarte, reitera-se que o desenvolvimento de atividades extracurriculares por parte de acadêmicos de graduação permite aos mesmos desenvolver habilidades pessoais, 
profissionais, além de técnicas e métodos científicos, outrossim, oportuniza-os aperfeiçoar o conhecimento acerca de uma área específica de atuação no mercado de trabalho, por fim, possibilita a percepção da vocação pelo aluno.

Como proposta para trabalhos futuros, sugere-se avaliar as contribuições das atividades de monitoria, pesquisa e extensão na formação acadêmica, profissional e pessoal do curso de engenharia de produção da UFPI, com a intenção de obter dados mais assertivos quanto ao desenvolvimento do ensino na área de engenharia, o qual auxiliarão na busca por estratégias de melhorias para a evolução dos programas citados.

\section{Agradecimentos}

Aos discentes que voluntariamente participaram da pesquisa e permitiram o desenvolvimento da mesma.

\section{REFERÊNCIAS}

AMARAL, R. As contribuições da pesquisa científica na formação acadêmica. Identidade Científica, Presidente Prudente-SP, v. 1, n. 1, p. 64-74, jan./jun. 2010.

AMORIM, T. B. et al. A importância da monitoria para o aprendizado de química. ABENGE: Revista de Ensino de Engenharia, v. 36, n. 2, 2017.

BRASÍLIA (Brasília). Lei no 9.394, de 20 de Dezembro de 1996. Lei de Diretrizes e Bases da Educação Nacional. Senado Federal. Brasília, pag. 64, 2005. Disponível em: https://www2.senado.leg.br/bdsf/bitstream/handle/id/70320/65.pdf.

BORATO, A.; PEREIRA, M. V. S.; BORDIN, D.; MARTINS, A. S.; FADEL, C. B. Valoração das práticas de ensino, pesquisa e extensão entre concluintes de Odontologia. Revista da ABENO, v. 18 n. 1, p. 103-115, 2018.

CHAVES M. J. C.; BARBOSA E. S.; THERRIEN S. M. N. Influência da monitoria acadêmica na formação do ser docente na enfermagem: Um relato de experiência. Revista COCAR, Belém. v.11, n.22, p. 202-227, 2017.

CHESANI, F. H.; WACHHOLZ, L. B.; OLIVEIRA, M. A. M.; LUZ, M. E.; FABRIS, F. A.; ENGEL, B. A indissociabilidade entre a extensão, o ensino e a pesquisa: $O$ tripé da universidade. Universidade Estadual de Ponta Grossa, Ponta Grossa, Brasil. Revista Conexão UEPG, v. 13, n. 3, pp. 452-461, 2017.

CRUZ, B. P. A.; MELO, W. dos S.; MALAFAIA, F. C. B.; TENORIO, F. G. Extensão Universitária e responsabilidade social: 20 anos de experiência de uma instituição de ensino superior. RGSA: Revista de Gestão Social e Ambiental, v. 5, p. 03-16, 2012.

DE PAULA, D. P. S.; GONÇALVES, M. D.; RODRIGUES, M. G. DE J.; PEREIRA, R. S.; FONSECA, J. R. O.; MACHADO, A. S.; GUIMARÃES, V. H. D.; ANDRADE, J. M. O.; PARAÍSO, A. F. Integração do ensino, pesquisa e extensão universitária na formação acadêmica: percepção do discente de enfermagem. Revista Eletrônica Acervo Saúde, n. 33, p. e549, 2019. 
FERREIRA, P. J. G.;; BONILLA, S. H.; GONÇALVES, R. F.; FRUGOLI, A. D.; FRUGOLI, P. A.; PAPALARDO, F.; SACOMANO, J. B. Indústria 4.0: Modelo de ensino para a formação de Engenheiros de Produção. Revista de Ensino de Engenharia, v. 38, n. 3, p. 93-105, 2019.

GUERSOLA, M. S.; CIRINO, P. D.; STEINER, M. T. A. Os papéis da universidade: Uma visão dos discentes de engenharia de produção. Revista de Ensino de Engenharia, v. 35, n. 2, p. 44-53, 2016.

LAKATOS, E. M.; MARCONI, M. A. Fundamentos da metodologia científica. 5 ed. São Paulo: Atlas, 2013.

PINTO, M. J. Ciência e ensino: contribuições da iniciação científica na educação superior. Avaliação: Revista da Avaliação da Educação Superior (Campinas), v. 22, n. 3, Sorocaba, 2017.

ROSA, L. M.; ANDRADE A. E.; BERNDT, L. K.; ANDERS, J. C.; RADÜNZ, V.; SOUZA, A. I. J. Atenção oncológica na atenção básica: projeto de extensão na formação de acadêmicos de enfermagem. Revista Eletrônica de Extensão, v. 14, n. 26, p. 107-118, 2017.

SANTOS, J.; ROCHA, B.; PASSAGLIO, K. Extensão universitária e formação no ensino superior. Revista Brasileira de Extensão Universitária, v. 7, n. 1, p. 23-28, 2016.

SANTOS, L. A.; BARROS, M. O.; MORENO, C. F.; BISPO, L. G. M.; NETTO, A. P. O. O Programa de Educação Tutorial como fator de influência no futuro da docência em engenharia: Estudos de caso na Universidade Federal de Alagoas. Revista de Ensino de Engenharia. v. 1, 2019.

SANTOS, M. P. Extensão universitária: Espaço de aprendizagem profissional e suas relações com o ensino e a pesquisa na educação superior. Revista Conexão UEPG, v. 8, n. 2, p. 154-163, 2012.

SILVA, A. R. A contribuição da extensão na formação do estudante universitário. 2011. 97 f. Dissertação (Mestrado em Educação) - Universidade Católica de Brasília, Brasília, 2011. Disponível em: https://bdtd.ucb.br:8443/ispui/handle/123456789/654. Acesso em: Dez 2019.

SILVA, B. G.; ARAÚJO, A. S.; SOUZA, T. D.; SANTANA, S. H. S.; FERREIRA, L. M. P. Percepção dos discentes de engenharia civil acerca do curso: estudo de caso da Universidade Federal do Sul e Sudeste do Pará. Revista de Ensino de Engenharia. v. 1, 2019.

SOUZA, J. F. T. DE; BIANCHI, M.; SOUZA, R. B. DE L. DE. Atividades complementares do curso de Ciências Contábeis da Universidade Federal do Rio Grande do Sul: Habilidades e competências do futuro profissional. Revista de Contabilidade Dom Alberto, v. 5, n. 9, p. 154-175, 2016.

\section{ENGINEERING EDUCATION - EXTRACURRICULAR ACTIVITIES}


Abstract: The present study aims to investigate the relationship between Production Engineering students at the Federal University of Piauí (UFPI) with extracurricular activities, investigating how they contribute to the qualified education of the student through the perception of the interviewed students. Thus, questionnaires were applied to students of Production Engineering at UFPl, duly enrolled in the period from 2017 to 2020. The results reveal a relative ignorance of the students in relation to what the university tripod represents, especially with regard to extension, in addition to from this it was noticed the insertion of these late in extracurricular programs, since the majority participation occurs only from the sixth (6th) period of course, it was also noted that the development of extra-class activities by academics of graduation allows them to develop personal and professional skills, as well as scientific techniques and methods. Therefore, the intervention of the university as an information and motivator of the academic participation in extracurricular activities is relevant.

Keywords: Engineering Education. Extracurricular activities. Qualified training. University tripod. Extension. 